\title{
Safety and tolerability of fixed antihypertensive combinations in blood pressure control: focus on olmesartan medoxomil and amlodipine combination
}

\author{
This article was published in the following Dove Press journal: \\ Integrated Blood Pressure Control \\ 15 November 2010 \\ Number of times this article has been viewed
}

\author{
Ijlal Uddin \\ Shakil Aslam \\ Division of Nephrology and \\ Hypertension, Georgetown University \\ Hospital, Washington, District of \\ Columbia, USA
}

\begin{abstract}
Hypertension is a major health problem worldwide and remains underdiagnosed and undertreated. Although public awareness and control of hypertension have improved over the last decade, only one-third of hypertensive patients achieve the rather conservative blood pressure (BP) goal of $<140 / 90 \mathrm{mmHg}$. Most hypertensive patients require more than one drug for optimum BP control. Expert panels recommend use of combination therapy with two or more medications for Stage 2 and higher hypertension and in high-risk patients. However, the use of multiple drugs reduces patient compliance. Fixed-dose combination therapy helps improve patient compliance and thus achieve the target BP. Dose titration of the individual constituent drugs is recommended before switching to an equivalent fixed-dose combination. Randomized, controlled trials have shown that the fixed-dose combination of amlodipine-olmesartan medoxomil is more effective in lowering BP than monotherapy with either of these agents, with a similar side effect profile.
\end{abstract}

Keywords: hypertension, target blood pressure, compliance, amlodipine, olmesartan

\section{Introduction}

Uncontrolled hypertension is the leading risk factor for cardiovascular disease and mortality worldwide. In 2000, approximately one billion people worldwide had hypertension, and this number is expected to increase by $60 \%$ to a total of 1.56 billion by 2025. ${ }^{1}$ Hypertension affects approximately $30 \%$ of adults in the industrialized nations, and blood pressure (BP) reduction to the recommended levels of $<140 / 90 \mathrm{mmHg}$ remains low at $32 \%$. Even in patients with chronic kidney disease who have higher risk of cardiovascular disease and associated co-morbidities, only $36.8 \%$ achieve the BP target recommended by the Joint National Committee on Prevention, Evaluation, and Treatment of High BP (JNC-7). Effective BP control to $<140 / 90 \mathrm{mmHg}$ reduces the incidence of heart failure by $50 \%$, myocardial infarction by $25 \%$, and stroke by $40 \%{ }^{2}$ The continued poor rates of BP control indicate a persistent need for improved antihypertensive therapy. Recent and ongoing clinical trials are utilizing combination therapy as initial treatment, especially in stage 2 hypertension $(160 \mathrm{mmHg}$ systolic or higher, diastolic $100 \mathrm{mmHg}$ or higher), or higher degrees of hypertension, or if BP is $>20 / 10$ $\mathrm{mmHg}$ above the target. Combination therapy may potentially confer the advantage of improved efficacy through additive or synergistic effects. Rational add-on therapies to renin-angiotensin-aldosterone system inhibitors include thiazide diuretics (especially in hypertensive patients exhibiting a low-renin state, eg, Afro-Caribbean and black
Correspondence: Shakil Aslam 3800 Reservoir Road, NW, 6 PHC, Washington, DC 200I5, USA

$\mathrm{Tel}+\mathrm{I} 2024449183$

Email sa93@georgetown.edu 
Americans), ${ }^{3}$ aldosterone antagonists, and calcium channel blockers. Table 2 lists some of the benefits of the fixed-dose combinations of antihypertensive agents.

\section{Advantages of combination therapy Better blood pressure control}

Initiating therapy with two agents is recommended for patients at high risk of a cardiovascular event or those with BP > 20/10 mmHg above goal (Table 1)., ${ }^{4,5}$ A rational strategy is to use agents with complementary mechanisms of action to enhance BP-lowering efficacy and prevent target organ damage. In experimental models, the combination of a calcium channel blocker with an agent that blocks angiotensin II improves endothelial function, inflammation, ventricular remodeling, and renal function to a greater degree than these drugs given as monotherapy. ${ }^{6}$ Several large randomized trials have shown that monotherapy is ineffective in reducing BP to a predetermined target range. For instance, in the Antihypertensive and Lipid Lowering Treatment to Prevent Heart Attack (ALLHAT) trial, only 27\% of 42,418 participants achieved the goal BP $(<140 / 90 \mathrm{mmHg})$ on monotherapy, from a baseline mean systolic BP of $146 \mathrm{mmHg}$ and $156 \mathrm{mmHg}$ for previously treated and untreated patients, respectively. ${ }^{7}$ In the Losartan Intervention For Endpoint (LIFE) trial, 90\% of 9193 participants with hypertension and left ventricular hypertrophy required more than one antihypertensive agent to achieve a similar BP target $(<140 / 90 \mathrm{mmHg})$ from a mean baseline of $174 / 97.8 \mathrm{mmHg} .{ }^{8}$ In the Avoiding Cardiovascular events through COMbination therapy in Patients LIving with Systolic Hypertension (ACCOMPLISH) trial, $32.3 \%$ of participants treated with benazepril-amlodipine or benazepril-hydrochlorothiazide required additional antihypertensive agents to reach the target BP of $<140 / 90 \mathrm{mmHg}$ $(<130 / 80 \mathrm{mmHg}$ for patients with chronic kidney disease)

Table I Guidelines for initial combination therapy

\begin{tabular}{|c|c|}
\hline Committee & $\begin{array}{l}\text { BP levels requiring initial combination } \\
\text { therapy }\end{array}$ \\
\hline JNC-735 & $\begin{array}{l}\text { Stage } 2(\geq 160 / 100 \mathrm{mmHg}) \mathrm{SBP}>20 \mathrm{mmHg} \\
\text { or DBP }>10 \mathrm{mmHg} \text { above the goal }\end{array}$ \\
\hline $\mathrm{NKF}^{36}$ & $\begin{array}{l}\mathrm{SBP}>20 \mathrm{mmHg} \text { above the goal according to } \\
\text { the stage of CKD and CVD risk }\end{array}$ \\
\hline $\mathrm{ADA}^{37}$ & $\mathrm{BP}>130 / 80 \mathrm{mmHg}$ and Type 2 diabetes \\
\hline $\mathrm{ESH}^{10}$ & High-risk patients according to total CVD risk \\
\hline \multicolumn{2}{|c|}{$\begin{array}{l}\text { Abbreviations: JNC-7, Seventh Report of the Joint National Committee on } \\
\text { Prevention, Detection, Evaluation, and Treatment of High Blood Pressure; SBP, } \\
\text { systolic blood pressure; DBP, diastolic blood pressure; NKF, National Kidney } \\
\text { Foundation; ADA, American Diabetes Association; ESH, European Society of } \\
\text { Hypertension; CKD, chronic kidney disease; CVD, cardiovascular disease; BP, blood } \\
\text { pressure. }\end{array}$} \\
\hline
\end{tabular}

from a baseline of 145/80 mmHg. ${ }^{9}$ In this randomized doubleblind trial, the target BP $(<140 / 90 \mathrm{mmHg})$ was achieved in over $78 \%$ of patients in the US cohort on the amlodipine-benazepril combination. In diabetics and in patients with chronic kidney disease the control rates were $72.5 \%$ and $70.8 \%$, respectively. These results demonstrate that monotherapy is ineffective in achieving the target BP in the majority of hypertensive individuals. This is reflected in the recommendations by several advisory panels (Table 1). The JNC-7 guidelines recommend initiating therapy with two antihypertensive agents in patients with Stage 2 and higher levels of BP. ${ }^{4}$ The European Society of Hypertension also recommends initial combination antihypertensive therapy in patients at high cardiovascular risk. ${ }^{10}$ Calcium channel blockers and antagonists of angiotensin II are highly effective and widely used antihypertensive agents, and are being increasingly offered in fixed-dose combinations. In addition to lowering BP, these drugs have vasculoprotective and pleiotropic properties..$^{11,12}$

\section{Better compliance with antihypertensive therapy}

Patient adherence to prescribed therapy and advice is a strong predictor of achieving BP control. ${ }^{13}$ The number of medications prescribed and the complexity of the treatment regimen are two important determinants of patient adherence. ${ }^{14}$ This has been shown in patients with a variety of different diseases. Adherence improves with fewer medications or pills prescribed. Reducing the number of pills by using combinations of drugs reduces non-adherence compared with the same drugs given separately, even with the same frequency. ${ }^{15}$ A meta-analysis of nine studies comparing fixed-dose combinations versus the same drugs given separately for treatment of diabetes, hypertension, tuberculosis, and human immunodeficiency virus infection, reported that fixed-dose combinations reduce the rate of non-adherence by $26 \% .{ }^{15}$ In this meta-analysis, a subgroup analysis of the four studies in hypertension showed that the fixed-dose combinations decreased the risk of medication non-adherence by $24 \%$ compared with free-drug combinations. In a study of 198 hypertensive patients randomized to receive diltiazem twice daily or amlodipine once daily, the

Table 2 Benefits of combination therapy in hypertension

- Better adherence to therapy and simplification of the therapeutic regimen

- Better blood pressure control than monotherapy

- Avoidance of dose-dependent adverse effects seen with higher doses of single agents

- Attenuation of the adverse effects of some agents when used alone - Complementary/synergistic vasculoprotective or pleiotropic effects. 
patients on a once-daily regimen took their study drug on a regular schedule $86 \% \pm 2 \%$ of times compared with $76 \% \pm 2 \%$ for those who were on a twice-daily dosing schedule. ${ }^{16}$ In a retrospective analysis of data from a pharmacy claims database in the US, ${ }^{17}$ adherence to a fixed-dose combination of amlodipine--benazepril was compared with adherence to free-dose combination therapy of the two agents. Patients given two or more prescriptions for the fixed-dose combination $(\mathrm{n}=2839)$ or the two components separately $(\mathrm{n}=3367)$ were identified and followed up for an average of 259 days and 247 days, respectively. Adherence to fixed-dose combination therapy (88\%) was significantly greater than for free combination therapy (69\%). The average annual cost of cardiovascular disease-related care per subject was also significantly lower in patients receiving the fixed-dose combination. Other studies have shown that adherence in hypertensive patients is inversely related to the BP control achieved. ${ }^{13}$

\section{Fixed-dose combination of amlodipine-olmesartan medoxomil}

The antagonists of angiotensin II have favorable metabolic, renal, cardiovascular, and quality of life effects compared with other antihypertensive agents. A post hoc analysis of the ACCOMPLISH trial reported that initial treatment with benazepril plus amlodipine slowed the progression of nephropathy to a greater extent than benazepril plus hydrochlorothiazide. Currently, the angiotensin II blockers are recommended as first-line drugs in patients with diabetes, proteinuria, and systolic heart failure. These drugs reduce BP and proteinuria, and slow the progression of diabetic nephropathy. ${ }^{18}$ In patients with Type 2 diabetes and overt nephropathy, the renoprotective action of angiotensin receptor blockers was evident in two large-scale trials. RENAAL (Reduction of Endpoints in non-insulin dependent diabetes mellitus [NIDDM] with the Angiotensin II Antagonist Losar$\tan$ Study $)^{19}$ demonstrated a $16 \%$ risk reduction in the primary composite endpoint of doubling of baseline serum creatinine, end-stage renal disease, or death from a cardiovascular cause, with losartan compared with placebo. The Irbesartan Diabetic Nephropathy Trial (IDNT) ${ }^{20}$ demonstrated superiority of irbesartan compared with amlodipine and conventional therapy in prevention of doubling of baseline serum creatinine, development of end-stage renal disease, or all-cause mortality, with similar BP reduction across all three cohorts.

Calcium channel blockers are effective in lowering BP and among the most commonly used antihypertensive drugs. Therefore, the angiotensin II antagonists are increasingly being used with calcium channel blockers as a fixed-dose combination. The fixed-dose combination of olmesartanamlodipine is the focus of this review. A brief discussion of the individual components will be followed by a discussion of the efficacy and tolerability of the fixed-dose combination of these agents.

\section{Amlodipine}

Amlodipine is a third-generation dihydropyridine calcium channel blocker and is the most commonly used agent in its class. More than $90 \%$ of amlodipine is absorbed and $95 \%$ of circulating amlodipine is bound to plasma proteins. Due to lack of significant first-pass hepatic metabolism, it has a prolonged duration of action, with a half-life of 35-45 hours. Like other calcium channel blockers, it acts by decreasing $\mathrm{Ca}^{2+}$ entry to cells through L-type $\mathrm{Ca}^{2+}$ channels, resulting in vascular smooth muscle relaxation. Its action peaks at 10-14 hours and steady-state plasma levels are reached in $7-8$ days. About $90 \%$ of amlodipine is converted to inactive metabolites via hepatic metabolism, and $60 \%$ of the metabolites are excreted in the urine. In patients with kidney disease, the pharmacokinetics of amlodipine are minimally changed. Dose adjustment may be needed in hepatic disease. Another property unique to amlodipine (with the possible exception of azelnidipine, not available in the US) is its antioxidant activity. Amlodipine is superior to felodipine, diltiazem, verapamil, and captopril at pharmacologically relevant doses in inhibiting lipid peroxidation in isolated membrane vesicles enriched with polyunsaturated fatty acids. ${ }^{21}$ This antioxidant property of amlodipine is independent of calcium channel blockade and is related to its chemical structure and direct physicochemical interactions with the membrane lipid bilayer. Due to its high lipophilicity, amlodipine is highly concentrated in the cell membrane, which enables it to scavenge free radicals effectively and break the lipid peroxidation chain reaction. Two abstractable hydrogen atoms associated with its aromatic rings further enhance its antioxidant activity. ${ }^{22}$ There is also evidence that amlodipine modulates the activity of PKC- $\alpha$, a powerful activator of nicotinamide adenine dinucleotide phosphate oxidase.

Amlodipine is very effective in lowering BP and reduces cardiovascular disease morbidity and mortality. This was shown in ALLHAT, ${ }^{23}$ which randomized 42,418 high-risk patients to receive chlorthalidone, amlodipine, lisinopril, or doxazosin. The study participants were $>55$ years of age, had Stage 1 or 2 hypertension with one additional cardiovascular disease risk factor, and $36 \%$ had diabetes. In this study, amlodipine was as effective as chlorthalidone in reducing the 
primary combined endpoint of fatal coronary heart disease or nonfatal myocardial infarction (relative risk, 0.98 ; 95\% confidence interval 0.90-1.07). Its efficacy in reducing combined coronary heart disease events and end-stage renal disease was comparable with that of chlorthalidone. However, the incidence of heart failure was 38\% higher in patients assigned to amlodipine than in those assigned to chlorthalidone in the absence of concomitant angiotensin II inhibitor therapy in either group. The incidence of other adverse effects was similar in both groups. In the Valsartan Antihypertensive Long-Term Use Evaluation (VALUE) trial, ${ }^{24}$ amlodipine was more effective than valsartan in reducing the prespecified secondary endpoint of fatal and nonfatal myocardial infarction ( $4.1 \%$ versus $4.8 \%, P=0.02)$. Overall, there were no differences in the primary composite endpoint of the time to first cardiac event. In this study systolic BP control $(<140 / 90 \mathrm{mmHg})$ was achieved in 4392 (58\%) of patients on valsartan and $4793(64 \%)$ of those on amlodipine. Diastolic BP $(<90 \mathrm{mmHg})$ control was achieved in 6652 (88\%) and $6940(92 \%)$ for valsartan and amlodipine, respectively. The target $\mathrm{BP}(<140 \mathrm{mmHg}$ systolic and $<90 \mathrm{mmHg}$ diastolic) was achieved in 4274 (56\%) patients in the valsartan group and $4694(62 \%)$ in the amlodipine group. The baseline BP in both groups was $154 / 88 \mathrm{mmHg}$. Both treatments were well tolerated. The incidence of edema was twice as high in amlodipine-treated patients $(32.9 \%)$ as in valsartan-treated patients (14.9\%), and hypokalemia was seen in the $6.1 \%$ of the patients treated with amlodipine versus $3.2 \%$ in the valsartan-treated group. A later substudy analysis of 7080 participants, analyzed according to whether they were still on monotherapy at the end of the first six months, showed that amlodipine increased the risk of congestive heart failure by $22 \%,{ }^{25}$ although the original analysis had shown no difference. Both of these large randomized trials suggested a higher risk of new onset congestive heart failure with amlodipine monotherapy. However, in patients with pre-existing congestive heart failure, addition of amlodipine does not increase mortality or morbidity. ${ }^{26}$ Furthermore, the increased risk of congestive heart failure seen with amlodipine monotherapy may be neutralized when it is combined with an angiotensin II antagonist. ${ }^{27}$

\section{Olmesartan medoxomil}

Olmesartan medoxomil, a prodrug hydrolyzed to olmesartan during absorption from the gastrointestinal tract, is a specific angiotensin II Type I receptor (AT-R $)_{1}$ antagonist. Olmesartan medoxomil has 12,500-fold greater affinity for the $\mathrm{AT}_{1}$ receptor than for the $\mathrm{AT}_{2}$ receptor. Olmesartan medoxomil has doses ranging from $2.5 \mathrm{mg}$ to $40 \mathrm{mg}$. The duration of inhibitory effect is related to the dose, with doses of olmesartan medoxomil $>40 \mathrm{mg}$ giving $>90 \%$ inhibition at 24 hours. The absolute bioavailability of olmesartan medoxomil is approximately $26 \%$, and its antihypertensive effect is achieved within 1-2 hours, with maximal reduction of BP achieved within 4-6 hours. The volume of distribution of olmesartan medoxomil is approximately $17 \mathrm{~L}$. Olmesartan medoxomil is highly bound to plasma proteins (99\%) and does not cross into red blood cells. It crosses the blood-brain barrier in rats poorly, but does cross the placental barrier and is distributed to the fetus. Olmesartan medoxomil is also distributed to milk at low levels in rats. Following the rapid and complete conversion of olmesartan medoxomil to olmesartan during absorption, no further metabolism takes place. Approximately 35\%-50\% gets excreted in the urine unchanged, while the remainder is eliminated in feces via the bile. Olmesartan medoxomil, like other angiotensin II antagonists, also exerts significant BP-independent beneficial effects. It reduces the expression of nicotinamide adenine dinucleotide phosphate oxidase subunits, the major source of free oxygen radicals in blood vessels.

\section{Olmesartan medoxomil-amlodipine combination therapy}

The efficacy and safety of olmesartan medoxomil-amlodipine combination therapy in the treatment of hypertension has been reported in several randomized controlled trials. In one trial, ${ }^{28} 1017$ patients with a baseline BP of $164 / 102 \mathrm{mmHg}$ were given open-label amlodipine $5 \mathrm{mg}$ daily as monotherapy. After eight weeks, the non-responders $(n=755)$ were randomized to receive placebo plus amlodipine $5 \mathrm{mg}$ or a combination of olmesartan medoxomil (10-40 mg) with amlodipine $5 \mathrm{mg}$ for eight weeks. At week 16, patients who had achieved diastolic BP $<90 \mathrm{mmHg}$ and/or systolic $\mathrm{BP}<140 \mathrm{mmHg}$ continued on randomized treatment for a further eight weeks. Patients with both systolic BP and diastolic BP $\geq 140 / 90 \mathrm{mmHg}$ at week 16 had their medication uptitrated to olmesartan medoxomil-amlodipine $20 / 5 \mathrm{mg}$, olmesartan medoxomil-amlodipine 40/5 mg, or olmesartan medoxomil-amlodipine $40 / 10 \mathrm{mg}$. The combination of olmesartan medoxomil 10-40 mg with amlodipine $5 \mathrm{mg}$ for eight weeks reduced mean systolic BP/diastolic BP by up to $16.8 \mathrm{mmHg}$ and $9.6 \mathrm{mmHg}$, respectively. The additional adjusted mean change in seated diastolic BP (primary endpoint) with last observation carried forward compared with placebo-amlodipine $5 \mathrm{mg}$ was $-2.0 \mathrm{mmHg}(P=0.02)$, $-3.7 \mathrm{mmHg}(P<0.0001)$, and $-3.8 \mathrm{mmHg}(P<0.0001)$ 
for olmesartan medoxomil-amlodipine 10/5 mg, 20/5 mg, and 40/5 mg, respectively.

In another randomized, double-blind, parallel-group, multicenter trial, ${ }^{29} 538$ patients with moderate-to-severe hypertension (systolic BP/diastolic BP $\geq 160 / 100 \mathrm{mmHg}$ ) were given open-label olmesartan medoxomil $20 \mathrm{mg}$ daily for eight weeks. At the end of eight weeks, patients whose $\mathrm{BP}$ was still above target (nondiabetics with systolic BP/ diastolic $\mathrm{BP} \geq 140 / 90 \mathrm{mmHg}$ and diabetics with systolic $\mathrm{BP} /$ diastolic $\mathrm{BP} \geq 130 / 80 \mathrm{mmHg}$ ) were assigned to amlodipine 5 or $10 \mathrm{mg} /$ day or a placebo in addition to olmesartan medoxomil, in a double-blind design. After eight weeks (with last observation carried forward), the adjusted mean change in seated diastolic BP from baseline was $-7.6 \mathrm{mmHg}$ for olmesartan medoxomil-placebo, $-10.4 \mathrm{mmHg}$ for olmesartan medoxomil-amlodipine $20 / 5 \mathrm{mg}(P=0.0006)$ and $-10.9 \mathrm{mmHg}$ for olmesartan medoxomil-amlodipine 20/10 mg $(P<0.0001)$. Mean changes in seated systolic BP from baseline with olmesartan medoxomil-amlodipine 20/5 mg and olmesartan medoxomil-amlodipine 20/10 mg were -16.1 and $-16.7 \mathrm{mmHg}$, respectively $(P<0.0001)$. Achievement of BP goal rates was significantly higher with olmesartan medoxomil-amlodipine 20/5 mg and olmesartan medoxomil-amlodipine $20 / 10 \mathrm{mg}(44.5 \%$ and $45.8 \%$, respectively; $P=0.0011$ and $P=0.0004$ ) versus olmesartan medoxomil-placebo (28.5\%). The incidence of drug-related adverse events was $8.9 \%$ for olmesartan medoxomil-placebo, $7.7 \%$ for olmesartan medoxomil-amlodipine $20 / 5 \mathrm{mg}$, and $11.3 \%$ for olmesartan medoxomil-amlodipine $20 / 10 \mathrm{mg}$ $(P=0.490)$.

Chrysant et $\mathrm{al}^{30}$ randomized 1940 patients according to a double-blind, placebo-controlled, factorial design in the COACH (The Combination of Olmesartan medoxomil and Amlodipine besylate in Controlling High blood pressure) trial. Mean age of the study population was 54.0 years, $54.3 \%$ were men, and $19.8 \%$ were aged $>65$ years. The mean baseline BP was $164 / 102 \mathrm{mmHg}$, and $79.3 \%$ of patients had Stage 2 hypertension. Patients were randomized to receive either an olmesartan medoxomil-amlodipine combination, olmesartan medoxomil alone, or amlodipine alone. The combination of olmesartan medoxomil-amlodipine caused dose-dependent reductions in seated systolic BP (from $-13.8 \mathrm{mmHg}$ with olmesartan medoxomil-amlodipine $10 / 5 \mathrm{mg}$ to $-19.0 \mathrm{mmHg}$ with olmesartan medoxomil-amlodipine 40/10 mg) and seated systolic BP (from $-23.6 \mathrm{mmHg}$ with olmesartan medoxomil-amlodipine $20 / 5 \mathrm{mg}$ to $-30.1 \mathrm{mmHg}$ with olmesartan medoxomil-amlodipine $40 / 10 \mathrm{mg}$ ) that were significantly greater than the reductions with the corresponding component monotherapies $(P<0.001)$. The number of patients achieving the BP goal ranged from 57/163 (35.0\%) to $84 / 158(53.2 \%)$ in the combination therapy group, from $32 / 160(20.0 \%)$ to $58 / 160(36.3 \%)$ in the olmesartan medoxomil monotherapy group, and from 34/161 (21.1\%) to 53/163 $(32.5 \%)$ in the amlodipine monotherapy group $(P<0.005$, combination therapy versus component monotherapies), compared with $14 / 160(8.8 \%)$ in the placebo group. The results of this study are summarized in Table 3 . The most common adverse events were edema (ranging from 9.9\% for olmesartan medoxomil $20 \mathrm{mg}$ to $36.8 \%$ for amlodipine $10 \mathrm{mg}$, compared with $12.3 \%$ for placebo) and headache (ranging from $2.5 \%$ for olmesartan medoxomil-amlodipine $10 / 5 \mathrm{mg}$ to $8.7 \%$ for olmesartan medoxomil $20 \mathrm{mg}$, compared with $14.2 \%$ for placebo). These studies show that a fixeddose combination of olmesartan medoxomil-amlodipine is effective and well tolerated, with an adverse effect profile similar to those of the individual drugs. Studies in special patient populations also confirm the efficacy and tolerability of this combination.

\section{Olmesartan medoxomil-amlodipine in specific populations}

A recently published $\mathrm{COACH}$ sub-study evaluated the longterm efficacy of the combination of amlodipine and olmesartan medoxomil with or without hydrochlorothiazide. ${ }^{31}$ The following findings were reported from this study and the subgroup analyses.

\section{Elderly patients}

Mean seated BP reductions for patients aged $<$ and $\geq 65$ years at week 52 were 31.0/19.2 $\mathrm{mmHg}$ and 38.3/21.5 $\mathrm{mmHg}$, respectively. Baseline seated BP and reduction in seated BP reductions were greater in patients eventually titrated to amlodipine-olmesartan-hydrochlorothiazide 10/40/25 mg per day. In general, the addition of hydrochlorothiazide caused greater seated BP reduction in patients aged $\geq 65$ years. Patients aged $\geq 65$ years had greater reductions in seated systolic BP at each titration step, compared with patients aged $<65$ years.

\section{Black patients}

Mean seated BP reduction at week 52 for black and nonblack patients was $30.8 / 18.7 \mathrm{mmHg}$ and $33.0 / 20.0 \mathrm{mmHg}$, respectively. Once again, baseline seated BP was highest and seated systolic BP reduction greatest in patients titrated to amlodipine-olmesartan medoxomil-hydrochlorothiazide $10 / 40 / 25 \mathrm{mg}$ per day. Approximately $20 \%$ of black patients 
Table 3 Proportion of patients achieving target blood pressure $(<\mid 40 / 90 \mathrm{mmHg}$ or $<130 / 80 \mathrm{mmHg}$ in patients with diabetes mellitus) by week eight/last observation carried forward according to subgroup and treatment regimen

\begin{tabular}{|c|c|c|c|c|c|c|c|c|}
\hline \multirow[t]{2}{*}{ Goal BP achieved (\%) } & \multicolumn{2}{|l|}{ Age } & \multicolumn{2}{|l|}{ Race } & \multicolumn{2}{|c|}{ Diabetes status } & \multicolumn{2}{|l|}{ BMI } \\
\hline & $<65$ & $\geq 65$ & Black & Nonblack & DM & non-DM & $<30 \mathrm{~kg} / \mathrm{m}^{2}$ & $\geq 30 \mathrm{~kg} / \mathrm{m}^{2}$ \\
\hline Placebo & 10.9 & 0 & 4.4 & 10.4 & 8.7 & 8.8 & 12.0 & 7.3 \\
\hline Amlodipine 10 mg & 32.8 & 31.1 & 43.6 & 29.0 & 8.7 & 36.4 & 30.3 & 34.4 \\
\hline Olmesartan $40 \mathrm{mg}$ & $4 I .1$ & 16.1 & 15.9 & 44.0 & 9.5 & 40.3 & 47.9 & 30.0 \\
\hline Amlodipine-olmesartan (10/40 mg) & 56.3 & 21.2 & 38.2 & 52.0 & 12.5 & 55.5 & 53.3 & 46.0 \\
\hline
\end{tabular}

Abbreviations: DM, diabetes mellitus; BMI, body mass index; BP, blood pressure.

remained on the initial dose of amlodipine-olmesartan medoxomil $5 / 40 \mathrm{mg}$ per day, compared with $34.9 \%$ of nonblacks. More black patients required titration to higher doses than nonblacks. Among black patients, 35.9\% were uptitrated to amlodipine-olmesartan medoxomilhydrochlorothiazide $10 / 40 / 25 \mathrm{mg}$ per day, and $49.7 \%$ on this dose achieved their seated BP goal at week 52 . Among black patients, the greatest seated BP reduction was observed in patients switching from amlodipine-olmesartan medoxomil-hydrochlorothiazide $10 / 40 / 12.5 \mathrm{mg}$ per day to amlodipine-olmesartan medoxomil-hydrochlorothiazide $10 / 40 / 25 \mathrm{mg}$ per day.

\section{Patients with diabetes}

At week 52, seated BP reduction from baseline in patients with diabetes was $34.2 / 19.9 \mathrm{mmHg}$ compared with $32.1 / 19.6 \mathrm{mmHg}$ in patients without diabetes. Only $26.9 \%$ of patients with diabetes achieved the seated BP goal of $<130 / 80 \mathrm{mmHg}$, whereas $72.9 \%$ of patients without diabetes achieved their seated BP goal of $<140 / 90 \mathrm{mmHg}$ with the initial dose of amlodipine-olmesartan medoxomil 5/40 mg per day. By week $52,48.0 \%$ of patients with diabetes were titrated to amlodipine-olmesartan medoxomil-hydrochlorothiazide $10 / 40 / 25 \mathrm{mg}$ per day, and $21.1 \%$ achieved the seated BP goal of $<130 / 80 \mathrm{mmHg}$.

In summary, the overall percentage of patients achieving their BP goal at week 52 on the combination of amlodipineolmesartan medoxomil was $61.0 \%$ for patients aged $\geq 65$ years, $68.1 \%$ for patients aged $<65$ years, $63.3 \%$ for blacks, $67.8 \%$ for nonblacks, $26.9 \%$ for patients with diabetes, and $72.9 \%$ of patients without diabetes. However, the study was not powered to show statistically significant differences between subgroups. Combination therapy was well tolerated, and no safety issues were noted. The most common adverse events were edema (ranging from 9.9\% with olmesartan medoxomil $20 \mathrm{mg}$ to $36.8 \%$ with amlodipine $10 \mathrm{mg}$, compared with $12.3 \%$ with placebo) and headache (ranging from $2.5 \%$ with olmesartan medoxomil-amlodipine $10 / 5 \mathrm{mg}$ to $8.7 \%$ with olmesartan medoxomil $20 \mathrm{mg}$, compared with $14.2 \%$ for placebo). Specifically, drug-related edema occurred in $7.0 \%, 11.1 \%, 9.1 \%$, and $10.7 \%$ of patients receiving amlodipine-olmesartan medoxomil 5/40 mg per day, amlodipine-olmesartan medoxomil 10/40 mg per day, amlodipine-olmesartan medoxomil-hydrochlorothiazide 10/40/12.5 mg per day, and amlodipine-olmesartan medoxomil-hydrochlorothiazide 10/40/25 mg per day, respectively.

Another study ${ }^{32}$ in 692 patients reported that coadministration of olmesartan medoxomil and amlodipine with a thiazide diuretic was better in achieving target BP, especially when a higher dose of the diuretic was used. Patients with moderate-to-severe hypertension who were inadequately controlled (BP $>140 / 90 \mathrm{mmHg}$ ) with amlodipine $5 \mathrm{mg}$ /day monotherapy and who subsequently completed 16 weeks of double-blind combination treatment with olmesartan medoxomil-amlodipine entered a 28-week open-label phase in which all patients initially received olmesartan medoxomilamlodipine 40/5 mg/daily. After four, 10, and 19 weeks, patients with inadequate BP control had their doses increased in a stepwise manner to olmesartan medoxomil-amlodipine 40/10 mg, olmesartan medoxomil-amlodipine-hydrochlorothiazide 40/10/12.5 mg, and olmesartan medoxomil-amlodipinehydrochlorothiazide $40 / 10 / 25 \mathrm{mg}$. Overall, $66.9 \%$ of patients achieved the target BP systolic BP $<140 \mathrm{mmHg}$ and diastolic $\mathrm{BP}<90 \mathrm{mmHg}$ for patients without diabetes, and systolic $\mathrm{BP}<130 \mathrm{mmHg}$ and diastolic $\mathrm{BP}<80 \mathrm{mmHg}$ for patients with diabetes.

Daiichi Sankyo, Inc. markets the combination of amlodipine-olmesartan medoxomil as AZOR ${ }^{\circledR}$. The different dose combinations of amlodipine-olmesartan medoxomil available in the US and Europe are 5/20, 10/20, 5/40, and $10 / 40 \mathrm{mg}$. Although monotherapy can be directly switched to fixed-dose combination, it is recommended to titrate the individual components separately until a suitable dose of each drug is established before switching to the fixed-dose combination. Caution and close monitoring of potassium and creatinine is needed while titrating angiotensin-converting enzyme inhibitors and angiotensin receptor blockers containing 
fixed-dose combinations. Dosage may be increased after two weeks, and a smaller dose combination should be chosen for elderly patients ( $>65$ years) and patients with chronic kidney disease. No specific data exist on drug interactions of this fixed-dose combination, and the guidelines for the individual components should be followed.

Peripheral edema was found to be significantly less common for olmesartan medoxomil-amlodipine 40/10 mg per day than for amlodipine monotherapy $10 \mathrm{mg} /$ day. ${ }^{28}$

A controversial effect of olmesartan medoxomil is that it improves myocardial function independent of BP reduction in hypertensive patients. Attenuation of inflammatory changes and myocardial hypertrophy may play an important role. ${ }^{33}$ Rosendorff et $\mathrm{al}^{34}$ randomized 102 patients with hypertension, left ventricular hypertrophy, and vascular hypertrophy to either amlodipine or olmesartan for 52 weeks in a Phase IIIb study. Add-on hydrochlorothiazide and terazosin were allowed if needed to achieve the target BP $(<140 / 90 \mathrm{mmHg}$ for non-diabetics and $<135 / 85 \mathrm{mmHg}$ for diabetics). At the end of 52 weeks, there were no significant changes in left ventricular compliance or carotid or femoral artery wall-tolumen ratios in either treatment group.

\section{Summary}

Hypertension is the leading cause of cardiovascular disease morbidity and mortality. Despite the availability of many effective antihypertensive agents, only $37 \%$ of the hypertensive patients achieve their target BP. Most patients with Stage 2 or higher hypertension and those with a high risk of cardiovascular disease require more than one agent to control their BP. Experts recommend initiating antihypertensive therapy using a combination of agents with complementary mechanisms of action in these patients. In long-term treatment of hypertension, single-pill combinations are associated with better drug adherence and better outcomes in comparison with free drug combinations.

Several randomized studies have demonstrated the superiority of using combination drug therapy, especially calcium channel blockers and the angiotensin II antagonists, in achieving target BP in various subgroups, while minimizing the incidence of adverse events seen with the treatment of hypertension using higher doses of a single agent. Addition of a thiazide diuretic to a calcium channel blocker, and a renin angiotensin aldosterone system antagonist combination further potentiates the antihypertensive effects of these drugs.

\section{Disclosure}

The authors report no conflicts of interest in this work.

\section{References}

1. Ezzati M, Lopez AD, Rodgers A, Vander Hoorn S, Murray CJ. Selected major risk factors and global and regional burden of disease. Lancet. 2002;360:1347-1360.

2. Effects of ACE inhibitors, calcium antagonists, and other bloodpressure-lowering drugs: results of prospectively designed overviews of randomised trials. Lancet. 2000;356:1955-1964.

3. Agodoa LY, et al. Effect of ramipril vs amlodipine on renal outcomes in hypertensive nephrosclerosis: a randomized controlled trial. JAMA. 2001;285:2719-2728.

4. Chobanian AV, et al. The Seventh Report of the Joint National Committee on Prevention, Detection, Evaluation, and Treatment of High Blood Pressure: the JNC 7 report. JAMA. 2003;289:2560-2572.

5. Mancia $\mathrm{G}$, et al. Guidelines for the management of arterial hypertension: The Task Force for the Management of Arterial Hypertension of the European Society of Hypertension (ESH) and of the European Society of Cardiology (ESC). Eur Heart J. 2007;28:1462-1536.

6. Weir MR. Targeting mechanisms of hypertensive vascular disease with dual calcium channel and renin-angiotensin system blockade. J Hum Hypertens. 2007;21:770-779.

7. Wright JT Jr, et al. Outcomes in hypertensive black and nonblack patients treated with chlorthalidone, amlodipine, and lisinopril. JAMA. 2005;293:1595-1608.

8. Dahlöf B, et al. Cardiovascular morbidity and mortality in the losartan intervention for endpoint reduction in hypertension study (LIFE): a randomised trial against atenolol. Lancet. 2002;359:995-1010.

9. Jamerson $\mathrm{K}$, et al. Benazepril plus amlodipine or hydrochlorothiazide for hypertension in high-risk patients. $N$ Engl J Med. 2008;359:2417-2428.

10. Guidelines Committee 2003 European Society of Hypertension-European Society of Cardiology guidelines for the management of arterial hypertension*. J Hypertens. 2003;21.

11. Shima E, et al. Calcium channel blockers suppress cytokine-induced activation of human neutrophils. Am J Hypertens. 21:78-84 (0 AD).

12. Chrysant SG, Chrysant GS. The pleiotropic effects of angiotensin receptor blockers. J Clin Hypertens (Greenwich). 2006;8:261-268.

13. Khalil SA, Elzubier AG. Drug compliance among hypertensive patients in Tabuk, Saudi Arabia. J Hypertens. 1997;15:561-565.

14. Bangalore S, Shahane A, Parkar S, Messerli FH. Compliance and fixeddose combination therapy. Curr Hypertens Rep. 2007;9:184-189.

15. Bangalore S, Kamalakkannan G, Parkar S, Messerli FH. Fixed-dose combinations improve medication compliance: A meta-analysis. Am J Med. 2007;120:713-719.

16. Leenen FH, et al. Patterns of compliance with once versus twice daily antihypertensive drug therapy in primary care: a randomized clinical trial using electronic monitoring. Can J Cardiol. 1997;13:914-920.

17. Wanovich R, Kerrish P, Gerbino PP, Shoheiber O. P-518: Compliance patterns of patients treated with 2 separate antihypertensive agents versus fixed-dose combination therapy. Am J Hypertens. 2004; 17:223 A.

18. Laffel LM, McGill JB, Gans DJ. The beneficial effect of angiotensinconverting enzyme inhibition with captopril on diabetic nephropathy in normotensive IDDM patients with microalbuminuria. North American Microalbuminuria Study Group. Am J Med. 1995;99:497-504.

19. Brenner BM, et al. Effects of losartan on renal and cardiovascular outcomes in patients with type 2 diabetes and nephropathy. $N$ Engl $J$ Med. 2001;345:861-869.

20. Lewis EJ, et al. Renoprotective effect of the angiotensin-receptor antagonist irbesartan in patients with nephropathy due to type 2 diabetes. N Engl J Med. 2001;345:851-860.

21. Mason RP, Walter MF, Trumbore MW, Olmstead EG Jr, Mason PE. Membrane antioxidant effects of the charged dihydropyridine calcium antagonist amlodipine. J Mol Cell Cardiol. 1999;31:275-281.

22. Mason RP, Campbell SF, Wang SD, Herbette LG. Comparison of location and binding for the positively charged 1,4-dihydropyridine calcium channel antagonist amlodipine with uncharged drugs of this class in cardiac membranes. Mol Pharmacol. 1989;36:634-640. 
23. ALLHAT Officers and Coordinators for the ALLHAT Collaborative Research Group. The Antihypertensive and Lipid-Lowering Treatment to Prevent Heart Attack Trial. Major outcomes in high-risk hypertensive patients randomized to angiotensin-converting enzyme inhibitor or calcium channel blocker vs diuretic: The Antihypertensive and LipidLowering Treatment to Prevent Heart Attack Trial (ALLHAT). JAMA. 2002;288:2981-2997.

24. Julius $\mathrm{S}$, et al. Outcomes in hypertensive patients at high cardiovascular risk treated with regimens based on valsartan or amlodipine: the VALUE randomised trial. The Lancet. 2004;363:2022-2031.

25. Julius S, et al. The Valsartan Antihypertensive Long-Term Use Evaluation (VALUE) Trial: Outcomes in Patients Receiving Monotherapy. Hypertens. 2006;48:385-391.

26. Packer M, et al. Effect of Amlodipine on Morbidity and Mortality in Severe Chronic Heart Failure. N Engl J Med. 1996;335:1107-1114.

27. Dahlof B, et al. Prevention of cardiovascular events with an antihypertensive regimen of amlodipine adding perindopril as required versus atenolol adding bendroflumethiazide as required, in the AngloScandinavian Cardiac Outcomes Trial-Blood Pressure Lowering Arm (ASCOT-BPLA): a multicentre randomised controlled trial. Lancet. 2005;366:895-906.

28. Volpe M, Brommer P, Haag U, Miele C. Efficacy and tolerability of olmesartan medoxomil combined with amlodipine in patients with moderate to severe hypertension after amlodipine monotherapy: a randomized, double-blind, parallel-group, multicentre study. Clin Drug Investig. 2009;29:11-25.

29. Barrios V, Brommer P, Haag U, Calderon A, Escobar C. Olmesartan medoxomil plus amlodipine increases efficacy in patients with moderate-to-severe hypertension after monotherapy: a randomized, double-blind, parallel-group, multicentre study. Clin Drug Investig. 2009;29:427-439.
30. Chrysant SG, Melino M, Karki S, Lee J, Heyrman R. The combination of olmesartan medoxomil and amlodipine besylate in controlling high blood pressure: $\mathrm{COACH}$, a randomized, double-blind, placebocontrolled, 8-week factorial efficacy and safety study. Clin Ther. 2008;30:587-604.

31. Oparil S, et al. Long-term efficacy of a combination of amlodipine and olmesartan medoxomil +/- hydrochlorothiazide in patients with hypertension stratified by age, race and diabetes status: a substudy of the COACH trial. J Hum Hypertens. 2010.

32. Volpe M, Miele C, Haag U. Efficacy and safety of a stepped-care regimen using olmesartan medoxomil, amlodipine and hydrochlorothiazide in patients with moderate-to-severe hypertension: an open-label, long-term study. Clin Drug Investig. 2009;29:381-391.

33. Futai R, Ito T, Kawanishi Y, Terasaki F, Kitaura Y. Olmesartan ameliorates myocardial function independent of blood pressure control in patients with mild-to-moderate hypertension. Heart Vessels. 2009;24;294-300.

34. Rosendorff C, Dubiel R, Xu J, Chavanu KJ. Comparison of olmesartan medoxomil versus amlodipine besylate on regression of ventricular and vascular hypertrophy. Am J Cardiol. 2009;104:359-365.

35. Chobanian AV, et al. The Seventh Report of the Joint National Committee on Prevention, Detection, Evaluation, and Treatment of High Blood Pressure: the JNC 7 report. JAMA. 2003;289:2560-2572.

36. K/DOQI clinical practice guidelines on hypertension and antihypertensive agents in chronic kidney disease. Am J Kidney Dis. 2004;43:11-13.

37. Summary of Revisions for the 2007 Clinical Practice Recommendations. Diabetes Care. 2007;30:S3.
Integrated Blood Pressure Control

\section{Publish your work in this journal}

Integrated Blood Pressure Control is an international, peer-reviewed open-access journal focusing on the integrated approach to managing hypertension and risk reduction. Treating the patient and comorbidities together with diet and lifestyle modification and optimizing healthcare resources through a multidisciplinary team approach constitute key

\section{Dovepress}

features of the journal. This journal is indexed on American Chemical Society's Chemical Abstracts Service (CAS). The manuscript management system is completely online and includes a very quick and fair peerreview system, which is all easy to use. Visit http://www.dovepress.com/ testimonials.php to read real quotes from published authors 